\title{
Structure and magnetic properties of a novel chloro-bridged polymeric cadmium(II) complex with pyridyl-substituted nitronyl nitroxide
}

\author{
C.F. Huang ${ }^{a}$, H.H. Wei ${ }^{\text {a.*, G.H. Lee }}{ }^{b}$, Yu Wang ${ }^{b}$ \\ - Department of Chemistn: Tumkang University. Tumsui 25137, Taisan \\ "Inserumentation Center. College of Science. National Tainum Universiṇ, Taipei, Taisan
}

Received 29 July 1997; received in revised form 29 September 1997; accepted 7 January 1998

\begin{abstract}
A complex of 2(2-pyridyl)-4,4,5,5-tetramethyl-4,5-dihydro- $\mid \mathrm{H}$-imidazol-1-oxy-3-N-oxide (NIToPy) with $\mathrm{Cd}(\mathrm{II}) \mathrm{Cl}_{2},\left[\left(\mathrm{CdCl}_{2}\right)_{3}\right.$ $\left.(\mathrm{NIToPy})_{2}\left(\mathrm{C}_{2} \mathrm{H}_{5}\right)_{2}\right]$. has been structurally and cryomagnetically characterized. The structure is based on a layered zigzagging polymeric chain along the (101) plane: the $\mathrm{Cd}(11)$ ions are linked into intinite chains by double chlorine bridges altemating between one $\mathrm{CdCl}_{4} \mathrm{O}_{2}$ and two $\mathrm{CdCl}_{4} \mathrm{NO}$ octahedral coordination units. The temperature-dependence of the magnetic susceptibility reveals the presence of a Heisenberg antiferromagnetic exchange interaction of a two spin $S=1 / 2$ system, with $J=-0.25 \mathrm{~cm}{ }^{\prime}$ associated with the intermolecular interaction between the NO groups of two neighboring NIToPy radicals. \$1998 Elsevier Science S.A. All rights reserved.
\end{abstract}

Nervirums: Crystul structures; Mugnesium complexes; Cadmium complexes; Nitronyl nitroxide complexes; Polymeric complexes

\section{Introduction}

There has been an increasing interest in the coordination elhemistry of cudmium in recent yeurs due to the increased recognition of its role in biologicul orgunisms $\mid[-5 \mid$, as well as in molecular-based materials $[6-8]$. In the quest for molecular-based materials with interesting properties, much attention has been given to one-, two- and three-dimensional extended solids which involve cadmium (6-10].

Complexes of the type $\mathrm{CdX}_{2}(\mathrm{X}=\mathrm{Cl}$ or $\mathrm{Br})$ with organic bases (c.g. pyridine) typically form one- or two-dimensional halogen-bridged chain compounds with six-coordination octahedral cadmium( II) $[10]$. Pyridyl-substituted nitronyl nitroxide, 2(2-pyridyl)4,4.5.5-lertrumethyl-4,5-dihydro- $1 \mathrm{H}$ imidazol-1-oxy-3-N-oxide (NIToPy), is a paramagnetic chelate ligand which can mediate a magnetic exchange interaction when bound to paramagnetic transition-metal halides such as $\mathrm{NiCl}_{2}$ (NIToPy) and $\mathrm{MnCl}_{2}$ (NIToPy) | 11 I]. Nevertheless, no NIToPy compounds with diamagnetic metals have been reported.

The 2-pyridyl-substituted nitronyl nitroxide ligand is especially attractive because the position of the pyridyl nitrogen atom is such that it could enforce the coordination of the NO

\footnotetext{
* Corresponding author.
}

group by the chelate effect. It is expected. therefore. that coordination will occur with a cadmium center. Our interest lies in the generation of polymeric structures in diamagnetic cadmium chloride with the paramagnetic chelate NIToPy ligand.

We describe here the sructural characterization and the magnetic properties of the cadmium(II) chloride complex with 2(2-pyridyl) 4.4.5.5-tetramethyl-4.5-dihydro $1 / 1 /$ imidazolyl-1-oxy-3-N-oxide (NIToPy) Schenie I.

\section{Experimental}

\section{I. Symthesis}

The 2-(2-pyridyl) -4,4,5,5-tetramethyl-4,5-dihydro- $1 \mathrm{H}$ imidazol-1-oxy-3-N-oxide (NIToPy) was prepared by following previously reported procedures $[12]$.

\subsection{1. $\left(\left(\mathrm{CdCl}_{2}\right)_{3}\left(\mathrm{NIT}, \mathrm{Py}_{2}\left(\mathrm{C}_{2} \mathrm{H}_{5} \mathrm{OH}\right)_{2}\right)\right.$}

A solution of $\mathrm{CdCl}_{2} \cdot \mathrm{H}_{2} \mathrm{O}(44.7 \mathrm{mg}, 0.2 \mathrm{mmol})$ in ethanol $\left(20 \mathrm{~cm}^{3}\right)$ and a solution of NIToPy $(46.8 \mathrm{mg}, 0.2 \mathrm{mmol})$ in ethanol $\left(10 \mathrm{~cm}^{3}\right)$ were mixed at room temperature by stiming. and the resulting solution was slowly evaporated in air for 
several days to give crystals suitable for $\mathrm{X}$-ray diffraction analysis. Anal. Calc. for $\mathrm{C}_{28} \mathrm{H}_{42} \mathrm{~N}_{6} \mathrm{O}_{6} \mathrm{Cl}_{6} \mathrm{Cd}_{3}: \mathrm{C}, 30.32 ; \mathrm{H}$, 3.79; N. 7.58. Found: C. 30.36; H, 3.75; N. 7.56\%. IR ( KBr disc): $u(N O), 1361 \mathrm{~cm}^{-1}(s)$.

\subsection{Physical measurements}

The IR spectrum of the title compound was recorded on a Bio-Rad FTS-40FTIR spectrophotometer as $\mathrm{KBr}$ pellets in the $4000-400 \mathrm{~cm}^{-1}$ region. X-band EPR spectra at $300 \mathrm{~K}$ for the complex in powder form were recorded on a Bruker ECS106 spectrometer. Temperature-dependence of the magnetic susceptibilities of the polycrystalline sample was measured between 4 and $300 \mathrm{~K}$ at a field of $1 \mathrm{~T}$ using a Quantum Design model MPMS computer-controlled SQUID magnetometer. Corrections for the diamagnetism of the complex were estimated from Pascal's constants.

\subsection{X-ray crystal structure analysis}

Crystallographic data were collected on an Enraf-Nonius CAD-4 diffractometer with graphite-monochromatized Mo $\mathrm{K} \alpha$ radiation at $25^{\circ} \mathrm{C}$. The unit cell parameters were determined from 25 reflections in the range $20 \leq 2 \theta \leq 32^{\circ}$. The details of data collection. crystalingraphic data and data reduction are summarized in Table 1.

The structure was solved by the standard heavy-atom method and refined by full-matrix least-squares based on $F$. Reliability factors were defined as $\boldsymbol{K}_{1}=\Sigma\left|\boldsymbol{F}_{0}-\boldsymbol{F}_{0}\right| / \Sigma\left|\boldsymbol{F}_{0}\right|$ and the function minimized was $R_{w} \equiv\left|\sum w\left(\left|F_{w}\right|=\left|F_{t}\right|\right)^{2}\right\rangle$ $\left.\left|\boldsymbol{F}_{w}\right|^{\frac{3}{2}}\right|^{1 / 2}$. where in the final least-squares calculation the weighting scheme $1 / \sigma^{2}\left(F_{10}\right)$ was used. Anisotropic thermal parameter refinement was performed. except for hydrogen atoms. All refinement calculations were performed using the NRCVAX computer program $[13$ ], Selected positional parameters of the non-hydrogen atoms are listed in Table 2.

\section{Reaults and discusetion}

\subsection{Description of the structure}

The results of the $X$-ray crystal structure analysis for $\left[\left(\mathrm{CdCl}_{2}\right)_{3}(\mathrm{NITOPy})_{3}\left(\mathrm{C}_{2} \mathrm{H}_{3} \mathrm{OH}\right)_{2}\right]$ is reproduced in Fig. $\mathrm{I}$. The selected bond distances and angles are given in Table 3 .

The crystal structure has features of the monoclinic space group C2/c: twofold axes and symmetn' centers. As illustruled in Figs. $I$ and 2. the structure comprises an alternating polymeric chain layer along the (101) plane with monometallic $\mathrm{Cd}(1) \mathrm{Cl}_{4} \mathrm{O}_{2}$ moieties located at the centres, and $\left[\mathrm{Cd}(2) \mathrm{Cl}_{2} \mathrm{NOI}_{2}\right.$ moieties. The $\mathrm{Cd}(\mathrm{II})$ ions of $\mathrm{Cd}(1)$ and $\mathrm{Cd}(2)$ are linked into an infinite chain by double chlorine bridges. The $\mathrm{Cd}(1) \cdots \mathrm{Cd}\left(2\right.$ ) and $\mathrm{Cd}(2) \cdots \mathrm{Cd}(2)^{\prime}$ distances in the molecule are $3.7634(11)$ and 3.7723 (14) $\dot{A}$. respectively. $\mathrm{Cd}(1)$, in $\mathrm{CdCl}_{4} \mathrm{O}_{2}$, is tetragonal as it is coordinated to four bridges of chlorine atoms. two $\mathrm{Cl}(3)$ and two $\mathrm{Cl}(4)$
Table 1

Crystallographic data for $\left[\left(\mathrm{CdCl}_{2}\right)_{3}(\mathrm{NIToPy})_{2}\left(\mathrm{C}_{2} \mathrm{H}_{5} \mathrm{OH}\right)_{2}\right]$

\begin{tabular}{|c|c|}
\hline $\begin{array}{l}\text { Formula } \\
M\end{array}$ & $\begin{array}{l}\mathrm{C}_{22} \mathrm{H}_{42} \mathrm{~N}_{6} \mathrm{O}_{6} \mathrm{Cl}_{6} \mathrm{Cd}_{3} \\
1108.2\end{array}$ \\
\hline Crystal system & monoclinic \\
\hline Space group & $C 2 / c$ \\
\hline$a(\dot{A})$ & $22.307(5)$ \\
\hline$b(\AA)$ & $10.481(3)$ \\
\hline $\begin{array}{l}c(\AA) \\
\beta\left(\left(^{\circ}\right)\right.\end{array}$ & $\begin{array}{l}20.282(3) \\
122.409(17)\end{array}$ \\
\hline$z$ & 4 \\
\hline$D_{c}\left(\mathrm{~g} \mathrm{~cm}^{-3}\right)$ & 2.212 \\
\hline$F(000)$ & 2552 \\
\hline$\mu\left(\mathrm{cm}^{-1}\right)$ & 13.589 \\
\hline Crystal size $(\mathrm{mm})$ & $0.40 \times 0.50 \times 0.60$ \\
\hline$R_{1}$ & 0.043 \\
\hline$R_{w}$ & 0.045 \\
\hline
\end{tabular}

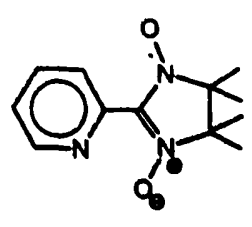

NITOPy

Scheme 1.

Tahle 2

Sclected final atomic positional parameters und $\boldsymbol{B}_{\text {sut }}$

\begin{tabular}{|c|c|c|c|c|}
\hline Alom & $x$ & $y$ & $:$ & $B_{\mathrm{Nw}}$ \\
\hline Cdil) & $=1 / 4$ & $1 / 4$ & 0 & $3.39(4)$ \\
\hline$C d(2)$ & $=0.1(x \times k \times 7(2+1)$ & $0.1 .1224(5)$ & $0.19401(3)$ & $2.85 .3(23)$ \\
\hline (111) & 0 & $0.3(x) 23(23)$ & $1 / 4$ & $3,53(1+1)$ \\
\hline$(112)$ & 0 & $=0 .(14+70(23)$ & $1 / 4$ & $3.5 .3(14)$ \\
\hline$C(1)$ & $=0.137547(10)$ & $0.1(x \times) 2(21)$ & $0.053103(9)$ & $4.61(11)$ \\
\hline$C /(4)$ & $-0.20473(9)$ & $0.29633(19)$ & $0.14473(9)$ & $3.96(10)$ \\
\hline$O(1)$ & $=0.19178(22)$ & $=0.0164(5)$ & $0.16978(23)$ & $3.7(3)$ \\
\hline$O(2)$ & $=0.0709(3)$ & $-(0.2692(5)$ & $0.3882(3)$ & $5.9(4)$ \\
\hline$O(3)$ & $-0.30116(25)$ & $0.0601(5)$ & $0.0139(3)$ & $5.2(3)$ \\
\hline$N(1)$ & $-0.08990(25)$ & $0.1055(5)$ & $0.3167(3)$ & $2.6(3)$ \\
\hline$N(2)$ & $-0.1676 .3(25)$ & $-0.1165(5)$ & $0.2139(3)$ & $2.9(3)$ \\
\hline$N(3)$ & $-0.1107(3)$ & $-0.2355(5)$ & $0.3184(3)$ & $3.5(3)$ \\
\hline
\end{tabular}

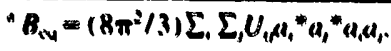

atoms, and two oxygen atoms from two $\mathrm{C}_{2} \mathrm{H}_{9} \mathrm{OH}$ ligands. The bond lengths of $\mathrm{Cd}(1)-\mathrm{Cl}(3), \mathrm{Cd}(1)-\mathrm{Cl}(4)$ and $C d(1)-O(3)$ are $2.5966(18), 2.5875(17)$, and $2.385(5) \dot{A}$. respectively. The intramolecular hydrogen bond $1 O(3)-$ $H \cdots O(1), \mid .82(4) \AA$ A exists between the $\mathrm{OH}$ group of ethanol ligands and the oxygen atom of the NO group. The $\mathrm{Cd}(1)-\mathrm{O}(3)-\mathrm{C}(13)$ bond angle is of $121.5(7)^{\circ}$.

In the bimetallic $\left[\mathrm{Cd}(2) \mathrm{Cl}_{2} \mathrm{NO}\right]_{2}$ moiety, the $\mathrm{Cd}(2)$ ions are coordinated by the four bridging chlorine atoms, and chelated by one nitrogen atom and one oxygen atom from the NITOPy ligands. The mean bond distance of $\mathrm{Cd}-\mathrm{Cl}$ is 2.598 A. Two $\mathrm{Cd}(2) \cdots \mathrm{Cd}(2)^{\prime}$ atoms are linked by a pair of bridging $\mathrm{Cl}(1)$ and $\mathrm{Cl}(2)$ atoms, and separated by $3.7723(4) \mathrm{A}$. 


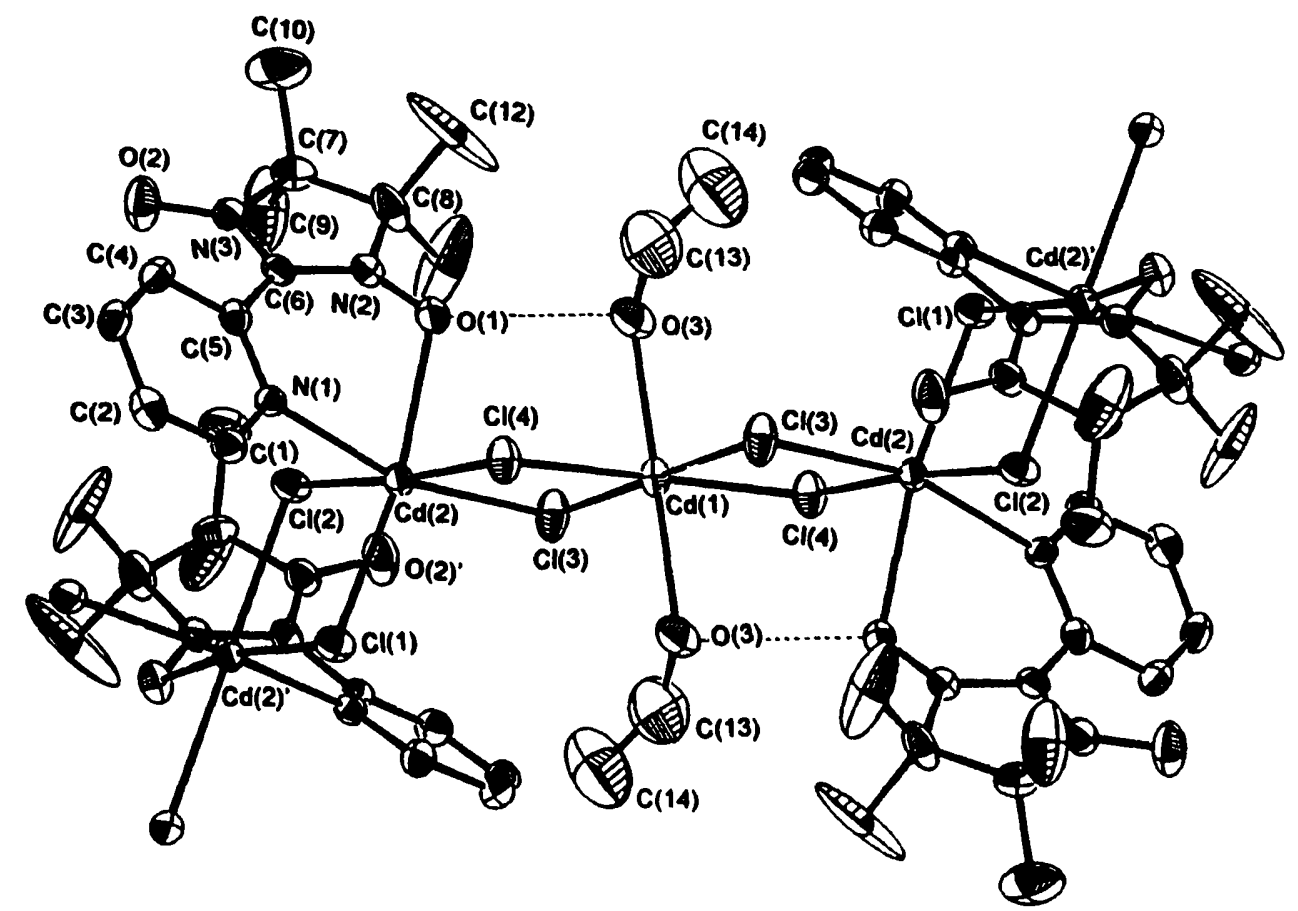

Fig. I. Structure of the $\mid\left(\mathrm{CaCl}_{2} h_{3}(\mathrm{NITOPy})_{2}\left(\mathrm{C}_{2} \mathrm{H}_{3} \mathrm{OH}\right)_{2}\right.$, showing the atom-lathelling scheme and $30 \%$ probability thermal ellipsoids. Hydrogen atoms are omitted for clurity. The hroken lines indicate the hydrogen bonds.

Tuble 3

Selected hond distunces $(\hat{A})$ and angles (")

\begin{tabular}{|c|c|c|c|}
\hline$C d(1)-C(1.3)$ & $2.5966(18)$ & $\mathrm{Cd}(1)-\mathrm{Cl}(4)$ & $2.5875(17)$ \\
\hline$C d(1)-O(3)$ & $2.38 .5(5)$ & $C d(2)-C l(1)$ & $2.5798(18)$ \\
\hline$C d(2)-C(1)$ & $2.6+55(19)$ & (idl 2$)-(113)$ & $2.5+16(18)$ \\
\hline$C d(2) \cdot(l(t)$ & $2 .(12(30)(10)$ & $(d)(2)-()(1)$ & $2.8(x)(d)$ \\
\hline$C(1(2)-N(1)$ & $2.373(5)$ & $N(2)-0(1)$ & $1.2(94171$ \\
\hline$N(3)-()(2)$ & $1.25417)$ & $(1(1), N(2)$ & $1.3 .34(9)$ \\
\hline$((0)=N(1)$ & $1.35 .3(9)$ & (d) 2$)$ C Cul $)^{\prime}$ & $.792 .3(1+1)$ \\
\hline$(d 11) \ldots C d(2)$ & $3.96 .12(11)$ & & \\
\hline$C(1,3)=C d(1)=C(1,3)$ & 190.9 & $(\|)+1)-c d(1)-(c)(+)$ & $|x|$ \\
\hline$C l(3)=C d(1)=C l(d)$ & $03.8(1)(6))$ & $(0(3)-(d)(1)-0(3)$ & 171.9 \\
\hline$C d(1)=O(3)=C(13)$ & $121.5(7)$ & $(0(3)-C(13) \cdot()(14)$ & $131.8(12)$ \\
\hline$C d(1)=C 1(3)=\operatorname{Cd}(2)$ & 1)4.18(6) & $(d(1)-C l(d)-C d(2)$ & (1). $21(6)$ \\
\hline$C l(3)-C d(2)-N(1)$ & $1(0.3 .16(1.3)$ & $O(1)-C d(2)-C l(1)$ & $167.56(11)$ \\
\hline$C d(2)-C(2)-C d(2)$ & $90.95(8)$ & $C d(2)-C l(1)-C d(2)^{\prime}$ & $93.96(8)$ \\
\hline$N(1)-C d(2)-O(1)$ & $74.88(16)$ & $C d(2)-O(1)-N(2)$ & $112.8(.3)$ \\
\hline$C(6)-N(2)-O(1)$ & $124.8(5)$ & $C d(2)-N(1)-C(5)$ & $125.9(4)$ \\
\hline$C d(2)-N(1)-C(1)$ & $115.9(4)$ & & \\
\hline
\end{tabular}

The $\mathrm{Cd}(2)-\mathrm{N}(1)$ (pyridine) and $\mathrm{Cd}(2)-\mathrm{O}(1)$ (nitroxide) bond distances are $2.373(5)$ and $2.400(4) \AA$. respectively.

The nitronyl nitroxide fragment $O(1)-N(2)-C(6)-$ $N(3)-O(2)$ in the NIToPy is almost coplanar, but makes a dihedral angle of $34.1(2)^{\circ}$ with the pyridyl ring, suggesting some resonance interactions between the pyridyl ring $\pi$ system and the $\mathrm{N}$-oxide- $\mathrm{N}$-oxyl system. The shortest intermolecular space between two non-bonding $O(2) \cdots O(2)^{\prime}$ atoms of $\mathrm{NO}$ groups, which belong to two different NIToPy radicals. is $6.426(8) \AA$. This intermolecular contact is large, thus the direct magnetic exchange interactions between two neighboring NO groups is negligible in the crystal lattice.

\subsection{Magnetic properties}

The EPR (at $9.80 \mathrm{GHz}$ ) spectra at 300$) \mathrm{K}$ of $\mid\left(\mathrm{CdCl}_{2}\right)_{3^{*}}$. $(\mathrm{NITOPy})_{2}\left(\mathrm{C}_{2} \mathrm{H}_{3} \mathrm{OH}\right)_{2} \mathrm{l}$ in benzene solution shows five major narrow lines in the ratio of $1: 2: 3: 2: 1$. as expected for coupling with two identical nitrogens of NO groups of NIToPy ligands. The $g$ value and the nitrogen hyperfine coupling constant $a^{\mathrm{N}}$ are 2.01 and $7.4 \mathrm{G}$, respectively.

$\chi_{m}$ and $\chi_{m} T$ versus $T$ plots for the complex are depicted in Fig. 3, where $\chi_{m}$ is the molar magnetic susceptibility. The $\chi_{\mathrm{m}} T$ value. $0.75 \mathrm{~cm}^{3} \mathrm{~mol}^{-1} \mathrm{~K}$. at $3(00 \mathrm{~K}$ is in good agreement with the value expected for two uncorrelated spin. $S=1 / 2$. 


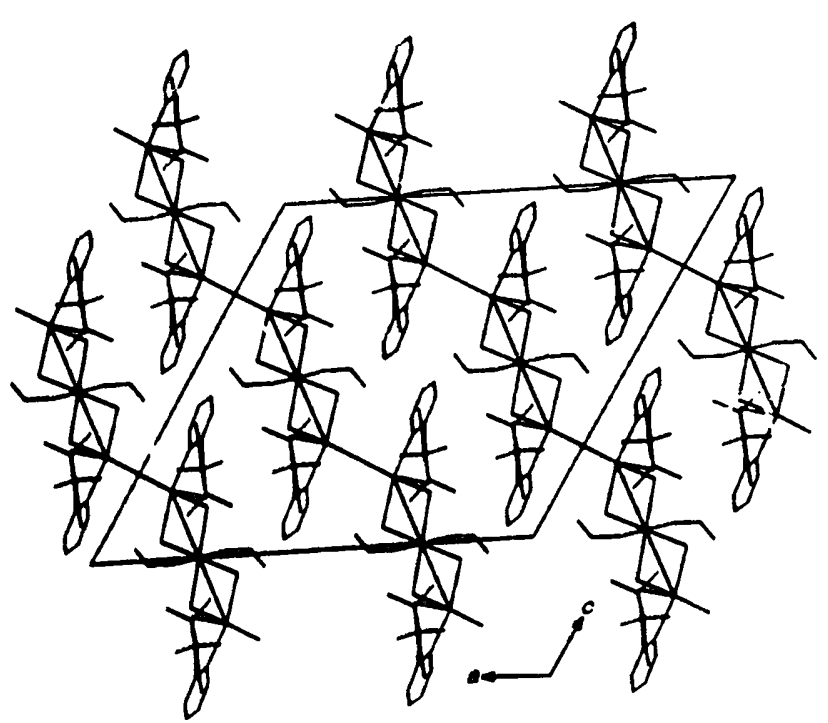

Fig. 2. View of a two-dimensional polymeric structure layer along the (101) plane.

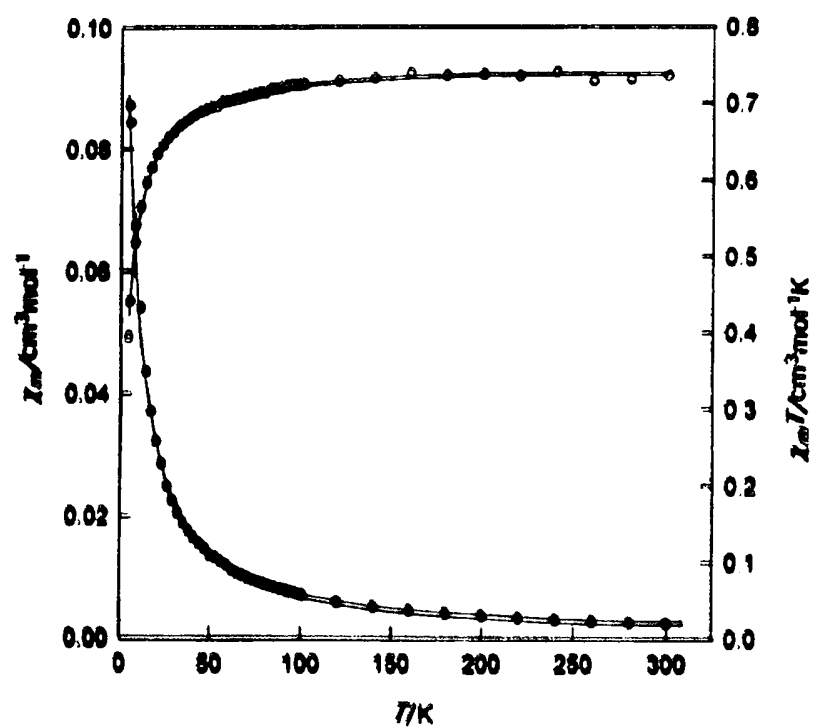

Fig. 3. Tempereturedependence of $x_{m}(O)$ and $x_{11} T(O)$ for $\left(\left(\mathrm{CdCl}_{z}\right)_{\text {t }}\right.$ (NITOPy) ${ }_{3}\left(\mathrm{C}_{2} \mathrm{H}_{3} \mathrm{OH}\right)_{2}$ I. The solid lines nepresent the values calculated with the parameters of the texl.

systems $\left(0.75 \mathrm{~cm}^{3} \mathrm{~mol}^{-1} \mathrm{~K}\right)$. On lowering the temperature. $X_{m} T$ decreases down $100.39 \mathrm{~cm}^{\prime} \mathrm{mol}^{-1} \mathrm{~K}$ at $4 \mathrm{~K}$, clearly indicating the existence of weak intrachain antiferromagnetic exchange interactions between two NO radicals in the solid.

As described in Section 3.1, the shortest intermolecular contact between the paramagnetic centers of NO groups. $O(2) \cdots O(2)$ ', is 6,426(4) $A$. This large separation suggests that direct magnetic coupling between two spins of NO groups is extremely difficult. Anticipating this result, we explain these dutu by considering only bimeullic $\left.\left[\left(\mathrm{CdCl}_{z}\right)_{2} \text { (NITOPy }\right)_{2}\right]$ moiety in the polymer chain with nearest-neighbor interactions between NO groups. From the stnctural features, there are two reliable superexchange pachways following the $\mathrm{NO}(1)-\mathrm{Cd}(2)-\mathrm{Cl}(1)-\mathrm{Cd}(2)^{\circ}-$ $O(1) N^{\prime}$ and $N O(1)-C d(2)-C l(2)-C d(2)^{\circ}-O(1) N^{\prime}$ bonds. Although exchange interactions by these pathways are expected to be weak, it is instructive to examine the results one gets by fitting a simple two spin $S=1 / 2$ model to our data by using the Bleanely-Bowers expression (Eq. (1)) [14] :

$$
\chi_{m}=2 N g^{2} \beta^{2} / k(T-\theta)[3+\exp (-2 J / k T)]^{-1}+N \alpha
$$

This results from considering the eigenvalues of the Heisenberg exchange Hamiltonian, $H=-2 J S_{1} \cdot S_{2}$. A very close agreement with the experiment is obtained with $J=$ $-0.25 \mathrm{~cm}^{-1}, \theta=-0.05 \mathrm{~K}, g=2.01$ ( from EPR), $N \alpha=60 \times$ $10^{-6} \mathrm{~cm}^{3} \mathrm{~mol}^{-1}$ and the disagreement factor $R=$ $\left[\Sigma\left(\chi_{\text {obs }}-\chi_{\text {calc }}\right)^{2} / \Sigma \chi_{\text {obs }_{x}}\right]^{1 / 2}=6 \times 10^{-5}$.

Finally, diamagnetic metal ions are believed not to mediate magnetic interactions. Recently however, several diamagnetic metal complexes with organic radicals as ligands showed that antiferro- or ferromagnetic interactions were possible through diamagnetic metal ions such as alkali metals $[15,16], \mathrm{Ga}$ (III) [17], Ti(IV) [18] and Cu(I) [19]. In the present paper, the cadmium ions appear to play an important role in the coupling pathways. Although only a weak antiferromagnetic interaction was observed between NIToPy radicals in this polymer chain, this is a new example of a polymeric diamagnetic cadmium compound with paramagnetic nitronyl nitroxide ligands. Further investigations will probe the nature of the interactions to find a strong ferromagnetic interaction of the cadmium ions with the other radical chelate ligands.

\section{Supplementary material}

Tables contuining complete utumic positions, anisotropic thermal parameters, hydrogen atom lecations, and bond distances and angles are available from the authors on request.

\section{Acknowledgements}

This work was supported by a grant of the National Science Council of Taiwan (NSC-86-2113-M-032-005).

\section{References}

III L.G. Marailli, T.J. Kistenmaxher. G.L. Eichhom in T.G. Spiro (ed.). Metal Ions in Biology. Vol. I. Wilcy. New York. 1980, p. 179.

I21 G.F. Nordherg. T. Kjellström. M. Nordberg in L. Friberg. C.G. Elinder. G.IF. Nordberg (eds.). Cadmium and Health: A Toxicologicul and Eppicemiological Appraisal CRC, Boca Ralon. Finland, 1985. Vol. 6. Ch. 6.

[3] E. Chapter. M. Bernhard. F.E. Brinckman. P.J. Sadler (eds.). The Importance of Chemical Speciation in Environmental Processes. Springer. Berlin. 1986.

(4) H. Strasdeit. W. Suak. S. Pohl. W.L. Driessen. J. Reedijk. Inorg. Chem. 27 (1988) 1557.

(5) T. Takayama. S. Ohuchida. Y. Koike. M. Watunabe, D. Hashizume. Y. Ohashi, Bull. Chem. Soc. Jpn. 69 ( 1996 ) 1579. 
[6] T. Soma, H. Yuge, T. Iwamoto, Angew. Chem., Int. Ed. Engl. 33 (1994) 1665 .

[7] B.F. Abraham. M.J. Hardie, B.F. Hoskins, R. Robson, E.E. Sutherland. J. Chem. Soc., Chem. Commun., ( 1994$) 1049$.

[8] M. Veith. S. Mathur, V. Huch, J. Am. Chem. Soc. 118 ( 1996) 903.

[9] D.D. Mak. T.C.W. Mak, Inorg. Chim. Acta 253 (1996) 15.

[10] R.H. Prince in S.G. Wilkinson, FRS, R.D. Gillard, J.A. McCleverty (eds.). Comprehensive Coordination Chemistry, Vol. 5, Pergamon, New York, 1989, p. 925.

[1I] D. Luneau, G. Risoun, P. Rey. A. Grand, A. Caneschi, D. Gatteschi. J. Laugier. Inorg. Chem. 32 (1993) 5616.

112] P.F. Richardion, R.W. Kreilick. J. Am. Chem. Soc. 99 (1977) 8183.
[13] E.J. Gabe, Y. Le Page, J.P. Charland. F.L. Ler. P.S. White, J. Appl. Crystallogr. 22 (1989) 384.

[14] B. Bleaney. Bowers, Proc. R. Soc. London. Ser. A 214 (1952) 451.

[15] K. Inoue, H. Iwamura. Chem. Phys. Lett. 207 ( 1993 ) 551.

[16] A. Misiolek. R. Huang. B. Kahr. J.E. Jackson. Chem. Commun. (1996) 2119

[17] D.M. Adams, A.L. Rheingold, A. Dei. D.N. Hendrickson, Angew. Chem., Int. Ed. Engl. 33 ( 1993) 391.

[18] S. Bruni, A. Caneschi, F. Cariati, C. Delfs, A. Dei, D. Gatteschi, J. Am. Chem. Soc. 116 ( 1994$) 1388$.

[19] H. Oshio, T. Watanabe, A. Ohto. T. Ito. H. Masuda, Inorg. Chem. 35 (1996) 472. 